Cahiers $d u$ MONDE RUSSE

\section{Cahiers du monde russe}

Russie - Empire russe - Union soviétique et États indépendants

$46 / 4 \mid 2005$

L'invention d'une politique humanitaire

\title{
Alter L. Litvin, John L. H. Keep, Stalinism
}

Nicolas Werth

\section{OpenEdition \\ Journals}

Édition électronique

URL : https://journals.openedition.org/monderusse/6593

DOI : 10.4000/monderusse. 6593

ISSN : $1777-5388$

Éditeur

Éditions de l'EHESS

Édition imprimée

Date de publication : 1 décembre 2005

Pagination : 898-900

ISBN : 2-7132-2057-2

ISSN : $1252-6576$

\section{Référence électronique}

Nicolas Werth, «Alter L. Litvin, John L. H. Keep, Stalinism », Cahiers du monde russe [En ligne], 46/4 | 2005, mis en ligne le 29 juin 2009, consulté le 03 septembre 2022. URL : http://

journals.openedition.org/monderusse/6593; DOI : https://doi.org/10.4000/monderusse.6593

Ce document a été généré automatiquement le 3 septembre 2022.

Tous droits réservés 


\title{
Alter L. Litvin, John L. H. Keep, Stalinism
}

\author{
Nicolas Werth
}

\section{RÉFÉRENCE}

Alter L. LITVIN, John L. H. KEEP, Stalinism: Russian and Western Views at the Turn of the Millenium. Londres, New York : Routledge, 2005, XI + 248 p.

1 Alter Litvin, professeur à l'université de Kazan, et John Keep, ancien professeur à l'université de Toronto et auteur d'ouvrages remarqués sur la révolution russe, ont eu l'excellente idée de faire le point sur les innombrables publications parues sur la période stalinienne, tant en russe qu'en anglais, en allemand ou en français, depuis l'ouverture des archives de l'ex-URSS.

2 L'objectif clairement fixé dès l'introduction de cet ouvrage - aider les étudiants en histoire soviétique à s'y retrouver dans cette masse de nouveautés - n'est cependant que partiellement réalisé. En effet, la « division du travail » adoptée par les auteurs (à Alter Litvin l'analyse des travaux en russe, à John Keep celle des travaux en langues occidentales) n'est guère satisfaisante. Non seulement elle est source de redites, mais en outre, au lieu de montrer sur quels terrains les historiens russes et occidentaux sont engagés dans un véritable dialogue, elle aboutit à une simple juxtaposition de travaux, sans aucune analyse des influences ou des fécondations réciproques.

Beaucoup plus courte, la première partie signée par Alter Litvin est aussi la plus faible et ne rend guère compte des nombreux débats historiographiques qui agitent le milieu des historiens russes. Ne serait-ce qu'avec leurs collègues ukrainiens, à propos des spécificités de la famine de 1932-1933 (un génocide du peuple ukrainien, pour l'immense majorité des historiens ukrainiens, alors que les historiens russes insistent, au contraire, sur le fait que la famine a aussi touché de très nombreux Russes, Cosaques, Kazakhs...). Les débats entre historiens russes proches du courant révisionniste américain et ceux plutôt portés sur l'approche totalitariste sont aussi passés sous silence. Deux des quatre 
chapitres de la première partie sont entièrement consacrés aux innombrables biographies de Stalin parues en russe, ainsi qu'au « rôle de Stalin comme leader ». Dans ces chapitres, Alter Litvin met sur le même plan des travaux de nature très différente, comme les ouvrages très solidement documentés et unanimement reconnus tant en Russie qu'en Occident signés d'oleg Khlevniuk, et les travaux de vulgarisation, à connotation sensationnaliste, de V. Rogovin. Le chapitre sur la Terreur de la fin des années 1930 est à la fois superficiel au regard des recherches très pointues menées par exemple par les historiens de l'association Memorial (notamment A. Roginskij, N. Petrov, N. Ohotin), à peine cités, et entaché de nombreuses erreurs factuelles (cf. p. 62, les données sur les répressions consécutives aux opérations terroristes secrètes de juilletaoût 1937).

4 À l'inverse, la seconde partie signée par John Keep tient toutes ses promesses et rend parfaitement compte du renouvellement des thématiques et des approches conceptuelles des historiens occidentaux - ou plus exactement d'une grande partie d'entre eux ; il est en effet dommage que les historiens italiens (dont certains, comme Andrea Graziosi, ont apporté une contribution essentielle aux recherches des dernières années) soient exclus du tableau.

Le premier chapitre de Keep (« Vieilles controverses, nouvelles approches ») montre très bien pourquoi les querelles des années 1980 entre « révisionnistes » et « totalitaristes » sont aujourd'hui largement dépassées. Keep analyse non sans quelque scepticisme l'émergence d'une école " postmoderne ", fondée pour une grande part sur les travaux de Michel Foucault. À juste titre, il critique une certaine histoire très sophistiquée qui tente de percer la constitution du « sujet soviétique » à partir de sources trop sélectives et trop éparses, telles que les journaux intimes. Pour Keep, citant l'historien russe Nikolaj Lomagin, «le concept de totalitarisme reste objectivement indispensable pour mieux comprendre l'essence même du régime qui a été établi en URSS » (p. 97). Pour autant, Keep n'en reste pas moins extrêmement attentif aux développements récents d'une histoire sociale qui, à la différence de celle pratiquée par les « révisionnistes » dans les années 1980, non seulement exploite une masse de sources nouvelles, mais ne «laisse plus l'État en dehors ». Le chapitre consacré aux « aventures de l'histoire sociale » est particulièrement remarquable par son analyse très fine des enjeux de cette histoire sociale profondément renouvelée, tant en ce qui concerne le monde rural (travaux de L.Viola, V.P. Danilov, S. Merl) que le monde ouvrier (travaux de D. Filtzer, S. Kotkin, J. Rossman). Les positions des uns et des autres sur le degré de résistance ou d'adhésion aux valeurs du système sont très bien expliquées.

Bien plus encore que son coauteur, John Keep fait une place importante aux études consacrées à la dimension centrale du stalinisme : la violence d'État. L'historiographie récente sur cette question est décortiquée, depuis les travaux sur les déportations, le Goulag (il manque ici malheureusement la monumentale Istorija Stalinskogo Gulaga en sept volumes parue fin 2004 aux éditions Rosspen, quelques mois seulement avant la parution de l'ouvrage de Litvin \& Keep), jusqu'aux études les plus récentes sur la Grande Terreur. Sur cette dernière question, Keep souligne, à juste titre, la faiblesse des positions de John Arch Getty, qui " persiste à voir des pressions venues d'en bas » dans ce qui apparait clairement, ainsi que l'a fortement démontré, parmi d'autres, Oleg Khlevniuk, comme un crime de masse planifié par Stalin et mis en œuvre par l'appareil du NKVD, dirigé par N.Ežov, les responsables régionaux du parti et de la police politique conservant, naturellement, une marge limitée d'autonomie dans le cadre de ce projet 
centralisé d'ingénierie sociale qui aboutit à l'extermination de quelque 700000 à 800000 personnes en seize mois.

7 L'émergence de nouveaux champs d'étude, qui apportent des correctifs importants aux postulats «classiques» du totalitarisme, tels que l'atomisation de la société ou l'annihilation de toute résistance sociétale au régime, ne doit pas banaliser la terrible violence du stalinisme, même si l'on sait encore peu de chose sur un sujet capital, celui des participants à cette violence - telle est l'une des conclusions fortes de John Keep, au terme de cet ouvrage certes inégal, mais tout de même très utile pour comprendre la formidable évolution de l'historiographie du stalinisme. 